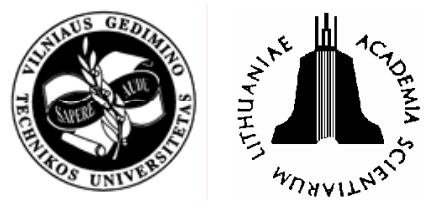

\title{
COMPACTING OF PARTICLES FOR BIAXIAL COMPRESSION TEST BY THE DISCRETE ELEMENT METHOD
}

\author{
Darius Markauskas, Rimantas Kačianauskas \\ Laboratory of Numerical Modelling of Vilnius Gediminas Technical University, Saulètekio al. 11, \\ LT-10223 Vilnius, Lithuania.E-mail:dm@fm.vtu.lt,rkac@fm.vtu.lt \\ Received 28 June 2005; accepted 06 Oct 2005
}

\begin{abstract}
Numerical simulation of the compacting of particles for the biaxial compression test using the discrete element method is presented. Compacting is considered as the first independent step required for a proper simulation of the entire compression process. In terms of the continuum approach, compacting is regarded as generation of the initial conditions. Three different compacting scenarios with differently manipulated loading history on the boundaries, namely, compacting by using the moving rigid walls, by the static pressure using flexible membranes as well as combining the above two methods are considered. Discrete element methodology and basic relations, as well as formulation of the compacting problem and computational aspects of compacting are presented in detail. Each of the scenarios is illustrated by the numerical results. It has been found that the combined compacting scenario yields the required initial conditions exhibiting the best physically adjustable state of particles.
\end{abstract}

Keywords: discrete element method, visco-elastic granular media, biaxial test, compacting of particles.

\section{Introduction}

Compression test is probably the dominating experimental procedure used for determining the strength and stress-strain properties of soils and other granular materials. In the compression test, a specimen is subjected to two independent external loadings - the controlled variable axial compression and constant lateral pressure. Triaxial tests generally comprise the deformation of a cylindrical specimen or rectangular parallelepiped, while biaxial tests allow us to investigate plane strain behaviour. On the other hand, biaxial test may be considered as a simplified model of threedimensional solid exhibiting the nature of the investigated phenomenon in hand.

Basically, compression tests were conducted to determine the macrospic characteristics of the granular media such as deformation moduli or angle of internal friction. A large majority of works are dealing with investigation of shearing characteristics and localisation of deformations of material related to occurring of shear band. For details on the compression tests, the reader is referred to classical textbooks, for example [1]. The work of Shinohara et al [2], describing the effect of the particle shape on the angle of internal friction may be considered as an example of experimental investigation using the triaxial compression test. Experimental setup using a special biaxial shear apparatus, allowing us to control general plane strain deformation is presented by Lanier and Jean [3].

Recently, numerical simulation has become a powerful alternative to investigating the behaviour of the granular media. It has some advantages over laboratory tests. This is partially because the experimentator cannot observe inter-particle processes. Another reason is a possibility to reproduce the identical properties of specimens and prescription of the required parameters.

Among currently used techniques, the discrete element method (DEM) is extensively applied to simulation of discrete and continuous problems of solid, fluid and molecular mechanics. The DEM, methodology initiated by P. Cundall and O. Strack [4], allows for the simulation of particle motion taking into account not only the obvious macroscopic domain geometry and constitutive relations between the macroscopic state variables, but also the interaction between the particles and their interaction with a physical environment.

The method opens up new vistas for investigation of these highly complicated entities, where the experimental measurements are extremely difficult because the duration of the interaction between the particles is very short and the displacements of individual particles are relatively small. On the other hand, the increasing capacity of the advanced computer technologies provides a basis for the development of computer-aided methods. Comprehensive reviews of DEM methodology and different computational aspects of the DEM are found in the papers of Sadd et al [5], Džiugys and Peters [6] and Langston et al [7]. Fundamental issues of DEM simulations and a continuum model are presented in the works of Luding et al [8] and Luding [9].

High computational expenses do not allow for a wide application of the DEM with 3D particle models to 
solving real scale problems. However, the use of the 2D particles may solve compression problems in a real time scale exhibiting major physical effects. A model based on 2D disk-shaped particles is most popular for simulation of compression, especially the biaxial compression tests, see Lanier and Jean [3], Ting at al [10], Sitharam [11], Liu et al [12], Jiang et al [13]. Uniaxial and biaxial compression tests of the sandstone specimen were simulated by Hunt et al [14]. Biaxial tests for granular material by applying a modified DEM with an additional elastic spring, a dashpot and a slider resisting rotation were considered by Ivashita and Oda [15]. Twodimensional polygon-shape particles were investigated by Mirghasemi et al [16].

Due to computational difficulties, direct simulation of triaxial tests is rather limited. Compression of spherical and clumped particles in a rectangular box was considered by Schmitt and Katzenbach [17]. Assessment of the influence of the particle size on the sharing characteristics of granular material by numerical simulation of the triaxial test using two- and threedimensional discrete elements was performed by Tsunekawa and Iwashita [18]. Uniaxial compression of the cylindrical specimen of cohesive geomaterial using an axi-symmetric model and 2D elements was studied numerically by Camborde et al [19].

In general, the applications of the DEM show a good agreement with macroscopic observations. By examining the fundamentals as well as using the numerical results obtained, a lot of problems should be solved to clarify and reduce the influence of the artificial computational effects occurring in DEM simulation. One of these is related to preparation of test specimens or, in terms of continuum, to prescription of the initial conditions.

Generally, three basic techniques, such as free compacting under gravity, particle expansion, and compacting by compression of boundaries are considered throughout the references. Free compacting is the simplest method used merely to generate the initial conditions in the granular flow during transportation. Using the expansion method [17] the radii of all particles are increased gradually to a desirable value. The contact force developed between any two particles during the growth process allows particles to move in order to turn specimen into a dense specimen. The expansion of radii is convenient when it is known what should be the porosity of the specimen.

Probably the most comprehensive review, focussing basically on compression methods of the topics discussed was provided by Jiang et al [13]. Originally [4], the compression methods were implemented by controlled inward motion of two (axial compression) or all four (isotropic compression) rigid walls resulting in compacting the particles. Obviously, the entire specimen is subject to compression (a single layer method), but the multi-layered method with the sequential compacting of separate layers has also been recently used. This type of compaction was applied by Schmidt [17], Lanier [3], Liu [12] to biaxial test.
The alternative way of implementing isotropic compression is to apply the prescribed pressure directly to stress-controlled flexible specimen boundaries. Tsunekawa and Iwashita [18] generated flexible boundaries of the three-dimensional cylindrical specimen using extra particles connected via Delaunay triangulation. This approach has limited application because complicated implementation of flexible boundaries leads to some additional expenses. Flexible boundaries composed of a chain of spherical particles were used by Ting et al [10] and Ivashita and Oda [15].

The compacting process with artificially generated initial conditions may affect the final results of the compression test. This effect was observed by Tsunekawa and Iwashita [18], but the causes of this phenomenon were not explained. The influence of the initial state and the sensitivity of equilibrium on the loading rate as well as the occurrance of oscillations were observed by Mirghasemi et al [16]. The importance of the initial conditions expressed in terms of the relationships between the confining pressure and macroscopic stresses as well as strains is most comprehensively illustrated by Sitharam [11].

Another drawback of the above compression method is associated with the difficulty to control pressure values, while equilibrium of the particles at pressure boundaries may be not attained when the specimen reaches a desired density.

The paper addresses the problem of compacting the particles of the specimen for the biaxial compression test. Compacting is considered as the first independent step required for a proper simulation of the entire compression process. In terms of the continuum approach, it is regarded as generation of the initial conditions. Three different compacting scenarios with differently manipulated loading histories on the boundaries, namely, the geometric compacting by using moving rigid walls, the static compacting using flexible membranes as well as a combination of the above methods are considered. Discrete element methodology and basic relations, formulation of the compacting problem and computational aspects of compacting are presented in detail. Each of the scenarios is illustrated by numerical results.

\section{Discrete element model and basic relations}

The two-dimensional DEM model is applied for simulation of the biaxial compression test. The granular media under compression presents an assembly of deformable particles in the form of discs. The DEM is a numerical technique aimed to track the dynamic motion of individual particles. Each of the particles is defined and considered separately, with its own mass, moment of inertia, radius and physical properties. The time-driven discrete element method [6] was used to simulate the time-dependent behaviour of particles.

In two dimensions, each particle $i(i=1, N)$, has three independent degrees of freedom (two translations and one rotation). The motion of each particle $i$ of the 
granular material in time $t$ is described by the second Newton law

$$
\begin{aligned}
m_{i} \frac{\mathrm{d}^{2} x_{i}}{\mathrm{~d} t^{2}} & =F_{x i}, \\
m_{i} \frac{\mathrm{d}^{2} y_{i}}{\mathrm{~d} t^{2}} & =F_{y i}, \\
I_{i} \frac{\mathrm{d}^{2} \theta_{i}}{\mathrm{~d} t^{2}} & =T_{i},
\end{aligned}
$$

where $x_{i}, y_{i}$ are components of the position vector $\mathbf{x}_{i}=\left\{x_{i}, y_{i}\right\}^{\mathrm{T}}, \theta_{i}$ is the orientation angle of the gravity centre, $m_{i}$ is mass and $I_{i}$ is the inertia moment of the particle.

Right-hand side parameters $F_{x i}, F_{y i}$, and $T_{i}$ present the resultants of gravity and inter-particle contact forces and torques, which act on the particle $i$, respectively:

$$
\begin{gathered}
F_{x i}=\sum_{j=1, j \neq i}^{N} F_{x i j}, \\
F_{y i}=\sum_{j=1, j \neq i}^{N} F_{y i j}+m_{i} g, \\
T_{i}=\sum_{j=1, j \neq i}^{N} T_{i j}=\sum_{j=1, j \neq i}^{N}\left(d_{x c i j} F_{y i j} \times d_{y c i j} F_{x i j}\right) .
\end{gathered}
$$

Here $\mathbf{d}_{c i j}$ is the geometric vector pointing from particle centre to contact point $C_{i j}$, while $g$ is gravity acceleration. The collision of particles is approximated by a representative overlap volume of particles in the vicinity of the impact point.

Inter-particle as well as particle-wall contact comprises the forces due to elastic deformation, viscous damping and friction. Some details for contact geometry model may be found in $[6,15,20]$.

The contact between two material particles is modelled by a spring and dashpot in both the normal and tangential directions and using an additional slider in tangential direction (Fig 1). The inter-particle force vector $\mathbf{F}_{i j}=\left\{F_{x i}, F_{y i}\right\}^{\mathrm{T}}$ describing the contact between the particles $i$ and $j$ acts on the contact point $C_{i j}$ and may be also expressed as the sum of the normal and tangential components:

$$
\mathbf{F}_{i j}=\mathbf{F}_{n, i j}+\mathbf{F}_{t, i j}
$$

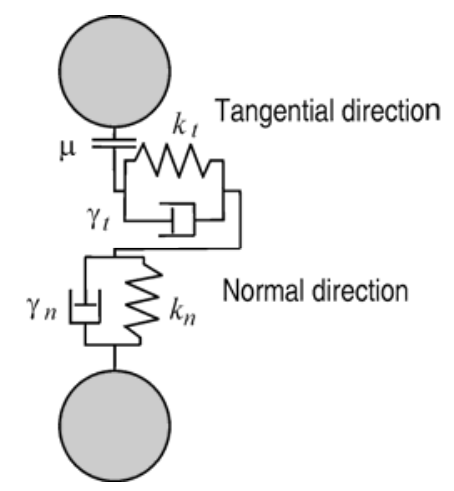

Fig 1. Inter-particle contact model
The normal forces involve elastic and viscous components. The elastic component of normal force $\mathbf{F}_{n, i j, \text { elastic }}$ corresponds to the unilateral nature of the contact and is actually the repulsion force. It is related to the amount of overlap $h_{i j}$ by the average secant normal contact stiffness of particles $i$ and $j$ :

$$
\mathbf{F}_{n, i j, \text { elastic }}=k_{n} h_{i j} \mathbf{n}_{i j},
$$

where $\mathbf{n}_{i j}$ is a unit vector pointing the direction of the contact surface through the centre of the overlap area towards the particle $i ; k_{n}$ is the normal spring stiffness.

The calculation of the viscous force component is based on the linear dependency of the force on the relative velocity $\mathbf{v}_{n, i j}$ of the particles at the contact point with a constant normal damping coefficient $\gamma_{n}$

$$
\mathbf{F}_{n, i j, v i s c o u s}=-\gamma_{n} m_{i j} \mathbf{v}_{n, i j},
$$

where $m_{i j}=\frac{m_{i} m_{j}}{m_{i}+m_{j}}$ is the reduced mass of the contacting particles $i$ and $j$.

The tangential force $\mathbf{F}_{t, i j}$ may be of the static or dynamic character. The elastic shear force with account of viscous damping forms the static shear friction. All subsequent relative shear displacements $\delta_{t, i j}$ are resulting in an additional increment of elastic shear force that is added to the current value

$$
\mathbf{F}_{t, i j, \text { elactic }}=k_{t} \delta_{t, i j} \mathbf{t}_{i j},
$$

where $\mathbf{t}_{i j}$ is the unit vector of the tangential contact direction; $k_{t}$ is the shear spring stiffness; $\delta_{t, i j}$ is the value of tangential displacement.

The viscous component in the tangential direction is modelled adequately to that in the normal direction (9):

$$
\mathbf{F}_{t, i j, \text { viscous }}=-\gamma_{t} m_{\mathrm{ij}} \mathbf{v}_{t, i j},
$$

where $\gamma_{t}$ is the tangential damping coefficient.

The nature of the dynamic force is related to the friction during and after gross sliding. This force is defined by introducing a slider in the model.

$$
\mathbf{F}_{t, i j, \text { dynamic }}=-\mu\left|\mathbf{F}_{n, i j}\right| \mathbf{t}_{i j} \text {. }
$$

The slip occurs when the shear force exceeds, in comparison to the normal force, a certain level, which depends on the dimensionless friction coefficient $\mu$.

When the contact forces are determined, the acceleration of each particle is calculated by the second Newton's law. New velocity and displacement are computed using a 5th-order Gear predictor-corrector scheme $[6,20]$.

In this study, the computer code called DEMMAT [21] is used for DEM.

\section{Compression problem}

The discrete element method is aimed to describe a system consisting of a large number of particles of various size, shape and material. The method actually presents the microscopic approach describing the behaviour of individual particles and inter-particle contacts. On the other hand, the particles in the system may demonstrate different behaviour and properties of 
the continuum on a macroscopic level. This system can be deformed as a solid body or it may expose flowability similar to that of a liquid or compressibility like that of gas. Soil is a representative medium, the behaviour of which, depending on particular conditions, may be considered as the behaviour of a mixture of particles or continuum in the form of a solid body or fluid.

In the above context, the discrete element method may be also interpreted as one of numerical techniques applied to the solution of continuum mechanics problems. It bridges the gap between macroscopic and microscopic models. More precisely, using DEM improves the continuum models by taking into account inter-particle contacts and internal dissipation and instabilities. Application of DEM serves as the basis for explaining the nature of multi-level mechanisms.

From the macroscopic point of view, the behaviour of a system of particles in the biaxial compression test may be treated as macroscopic behaviour of the twodimensional continuum. In most general terms, continuum formulation of the compression test presents the initial value problem. The problem domain is twodimensional rectangular domain (Fig 2), inside which the material and all mechanical properties, including material density, are defined a priori.

As used in mechanics of solids, the differential equations of dynamic (in a simplified case, static) equilibrium are formulated in terms of the unknown time-dependent displacement vector field $\mathbf{u}(\mathbf{x}, t)$ :

$$
\operatorname{Au}(\mathbf{x}, t)=\mathbf{F}(\mathbf{x}, t) \text {. }
$$

The initial conditions for the continuous field variable are defined as

$$
\mathbf{u}(\mathbf{x}, 0)=\mathbf{u}_{0},\left.\frac{\mathrm{d} \mathbf{u}(\mathbf{u}, 0)}{\mathrm{d} t}\right|_{t=0}=\mathbf{v}_{0} .
$$

In terms of the discrete approach, equilibrium equations (13) are replaced by Eq (1-3) written for individual particles. The initial state of the motion (14) should be defined by the initial conditions for an individual particle imposed in time $t_{0}=0$.

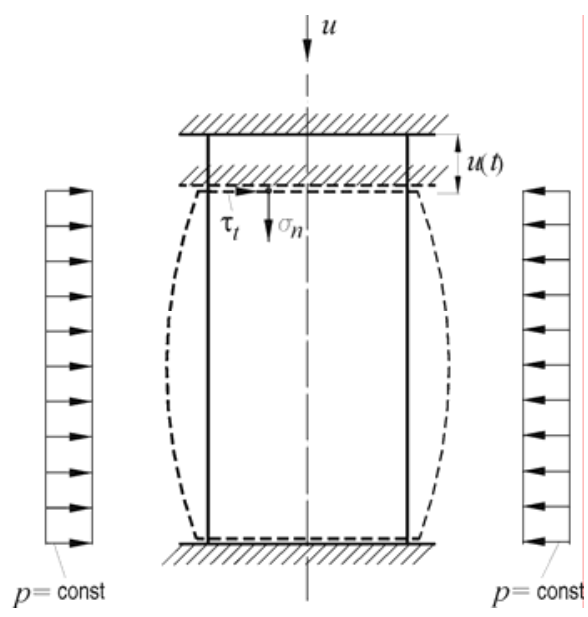

Fig 2. Compression test problem with boundary conditions

$$
\mathbf{x}_{i}\left(t_{0}\right)=\mathbf{x}_{0 i},\left.\frac{\mathrm{d} \mathbf{x}_{i}}{\mathrm{~d} t}\right|_{t=t_{0}}=\mathbf{v}_{0 i} .
$$

Here, $v_{0 i}$ stands for the initial velocity of the particle $i$. The correct setting up of conditions (15) is a complicated task because of particle positioning. In order to achieve the real physical state in DEM, the initial conditions are implemented numerically by preliminary simulation of the particle state using the same Eq (1-3). Finally, instead of dealing with the conditions defined by Eq (6), the initial conditions are defined in time $t_{l}$

$$
\mathbf{x}_{i}\left(t_{1}\right)=\mathbf{x}_{1 i},\left.\frac{\mathrm{d} \mathbf{x}_{i}}{\mathrm{~d} t}\right|_{t=t_{1}}=\mathbf{v}_{1 i} .
$$

Here, $t_{l}$ is the time required for simulation of the initial conditions, while the given values of $\mathbf{x}_{1 i}$ and $\mathbf{v}_{1 i}$ are obtained in preliminary simulation.

Two types of boundary conditions are considered for a description of the granular state during compression. The rigid wall boundary conditions are used to define the interface of material with a rigid surface. In terms of continuum, a rigid wall allows us to implement only standard geometric boundary conditions of Dirichlet type restricting particle motion $u_{n}$ in normal direction

$$
u_{n i}(t)=u(t) .
$$

In terms of the discrete element, the concept of a rigid wall is much more powerful. The discrete approach also allows us to impose tangential friction, where by the evaluation of contact, the rigid walls may be treated as particles of infinite radius and mass. Eq (16) is the unilateral condition restricting the motion of the particle only outside the granular domain. Furthermore, motion and rotation of the rigid walls may be imposed in the same manner.

The static boundary conditions on the free surface may be implemented by adding pressure $p$ directly to the particle $i$ :

$$
F_{n i}(t)=p(t) A_{i},
$$

where $A_{i}$ presents the effective surface area of the particle $i$.

Different manipulations are used to form various compacting scenarios.

\section{Compacting algorithm and scenarios}

Current investigation is restricted to the consideration of the compression of the boundaries. The specimen was compacted according to three different scenarios. Each of the scenarios is implemented by different time sequences of the prescription of the boundary conditions (17) or (18) as illustrated in Fig 2. The first scenario is used to prepare the specimen for the biaxial test with all four rigid walls. In the second scenario, the side walls were replaced by flexible membranes immediately after the generation of specimen. These membranes imitate rubber membranes used in the experiment. The third scenario is a combination of the first and the second scenarios. 
According to the first scenario, the specimen is compacted by applying displacements for all four rigid walls until the required porosity is achieved. After generating the specimen a simulation of the biaxial test could be performed. In such an analysis, constant pressure on the side walls is kept, while the upper and the bottom walls are moved inward.

In the experiments with a constant pressure application on the sides of the specimen, a flexible rubber membrane is often used. In the present numerical analysis, a membrane consisting of the chain of particles is introduced. This membrane is similar to the membrane used by Iwashita and Oda (2000) [15]. According to the second scenario, flexible membranes on the sides of the specimen were introduced immediately after the generation of the particles to obtain a compacted specimen with flexible membranes. Pressure on each particle of the membrane and on the top and bottom walls is gradually increased from zero to the required value.

The third way of obtaining the compacted specimen was implemented by combining the first two ways. At the very beginning of the compaction, the rigid walls on both sides and on the top and bottom are introduced. The specimen is compacted isotropically by moving the walls inward at a prescribed speed. The compression is suspended before a considerable force will start to act the boundaries. From that point, the side walls are replaced by flexible membranes and pressure is gradually increased to the required value. The compression test can be performed on this compacted specimen by keeping constant pressure on both sides and applying displacements to the top and bottom walls.

\section{Numerical results and discussion}

The current study is aimed to prepare the specimen for $2 \mathrm{D}$ biaxial test simulation using grain size distribution presented in Fig 3. This distribution was obtained by upscaling the grain size distribution of Karlsruhe sand presented by Schmitt (2003) [17] by the factor four. 2658 particles were generated and placed in the rectangular area of the size $5 \times 10 \mathrm{~cm}$. The specimen of the unit thickness was used. The model parameters are given in Table 1. The time step in simulations was selected as $\Delta t \leq 1 / 10 \Delta t_{c}$, where $\Delta t_{c}$ equals $2 \sqrt{m / k}$ [12].

Table 1. The parameters selected for the present simulation study

\begin{tabular}{l|c}
\hline \multicolumn{1}{c|}{ Quantity } & Value \\
\hline Number of particles & 2658 \\
\hline Radii of particles & $0,5-3,5 \mathrm{~mm}$ \\
\hline Time step $(\Delta t)$ & $1 \cdot 10^{-7} \mathrm{~s}$ \\
\hline Particle density & $2600 \mathrm{~kg} / \mathrm{m}^{3}$ \\
\hline Coefficient of friction between particles $(\mu)$ & 0,5 \\
\hline $\begin{array}{l}\text { Coefficient of friction between particle and } \\
\text { wall }(\mu)\end{array}$ & 0,0 \\
\hline $\begin{array}{l}\text { Coefficient of friction between particle and } \\
\text { membrane }(\mu)\end{array}$ & 0,0 \\
\hline Normal spring constant $\left(k_{n}\right)$ & $1,5 \cdot 10^{6} \mathrm{~N} / \mathrm{m}$ \\
\hline Tangential spring constant $\left(k_{t}\right)$ & $1,0 \cdot 10^{6} \mathrm{~N} / \mathrm{m}$ \\
\hline Normal damping coefficient $\left(\gamma_{n}\right)$ & $500 \mathrm{~s}^{-1}$ \\
\hline Shear damping coefficient $\left(\gamma_{t}\right)$ & $500 \mathrm{~s}^{-1}$ \\
\hline
\end{tabular}

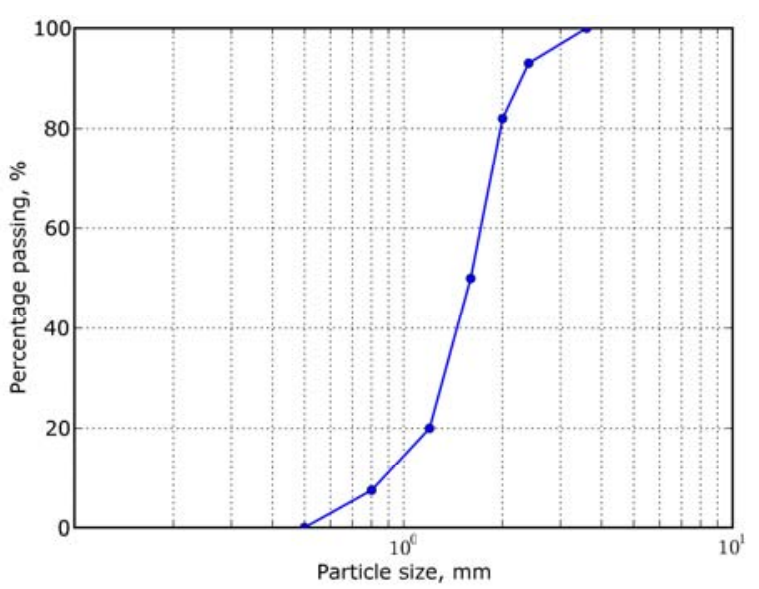

Fig 3. Size distribution of particles used in DEM analysis

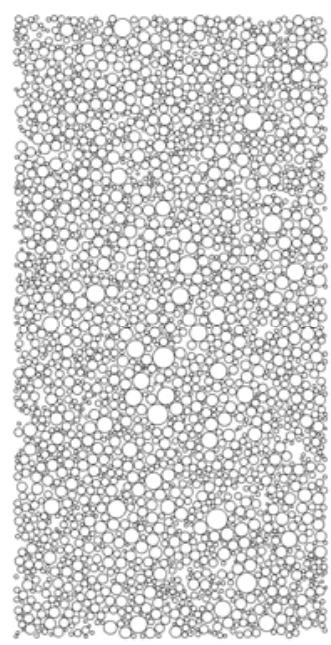

Fig 4. Initial arrangement of particles

The first scenario described in the previous section is considered. The generated specimen (Fig 4) is compacted by moving all four walls inward at constant speed until the wall displacement is equal to $3 \mathrm{~mm}$. Four compaction processes were simulated by applying different speeds to the walls reaching $0,50 \mathrm{~m} / \mathrm{s}, 0,20 \mathrm{~m} / \mathrm{s}$, $0,05 \mathrm{~m} / \mathrm{s}$ and $0,01 \mathrm{~m} / \mathrm{s}$, respectively. The resultant reaction forces acting on the bottom wall are shown in Fig 5. During a fast compaction the reaction force has

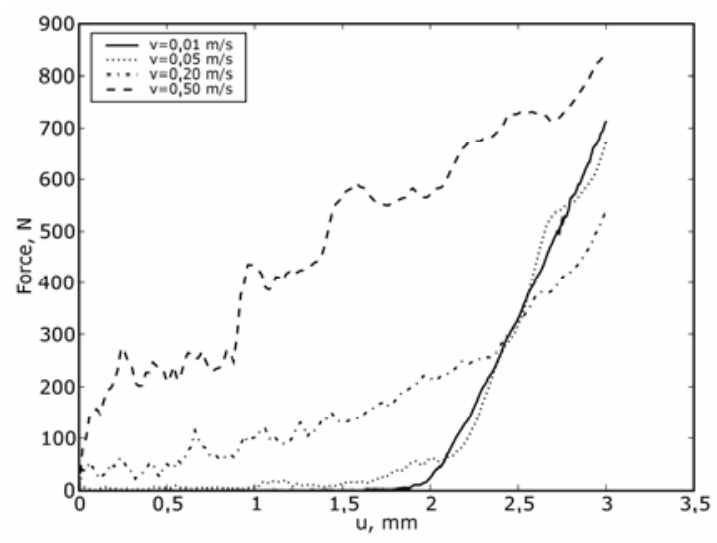

Fig 5. The influence of the wall speed on the reaction force 
a)

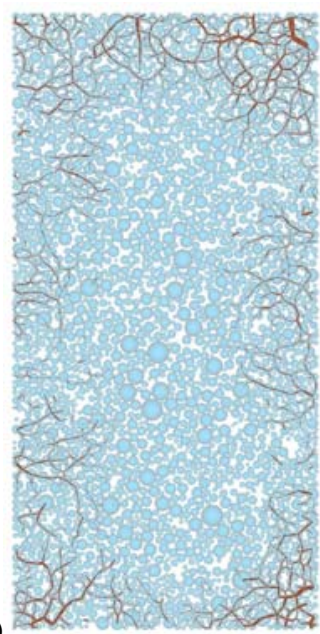

b)

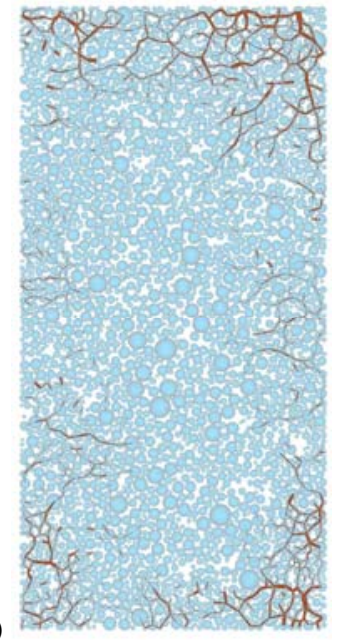

c)

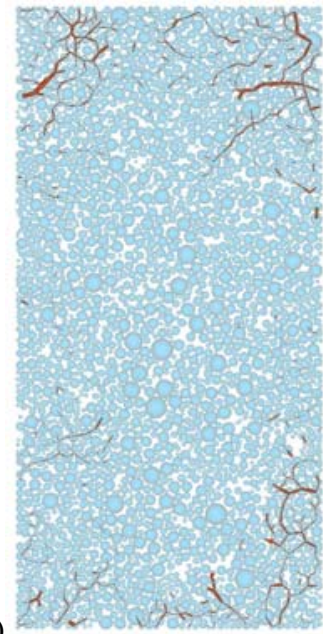

d)

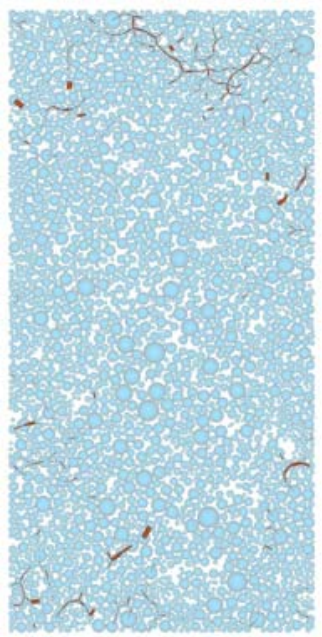

Fig 6. The force network from the first scenario: a) $u=1 \mathrm{~mm}, v=0,50 \mathrm{~m} / \mathrm{s}, F_{\max }=77,5 \mathrm{~N}$; b) $u=1 \mathrm{~mm}, v=0,20 \mathrm{~m} / \mathrm{s}$, $F_{\max }=18,9 \mathrm{~N}$; c) $u=1 \mathrm{~mm}, v=0,05 \mathrm{~m} / \mathrm{s}, F_{\max }=2,83 \mathrm{~N}$; d) $u=1 \mathrm{~mm}, v=0,01 \mathrm{~m} / \mathrm{s}, F_{\max }=0,27 \mathrm{~N}$

already increased at the first stage. This reaction may be accounted for the system's dynamics. In fast compaction the forces between the particles near the boundary do not have time to be transmitted to the interior particles. Therefore the layers near the boundary are compacted more tightly than the interior ones. It is illustrated by the force network in Fig 6. To eliminate the influence of the dynamics, the compression should be performed at low speed. As shown in Fig 5, the speed of the specimen walls equal to $v=0,01 \mathrm{~m} / \mathrm{s}$ can be applied. The compacted specimen is shown in Fig 7.

In compacting the specimen, the force acting on the wall does not increase significantly until about $u=2,0 \mathrm{~mm}$. The same change can be seen when the translational kinetic energy of the specimen is changed (Fig 8). This alteration could be explained by the alteration of the internal structure of the specimen as follows. Until the displacement is equal to about $1,8 \mathrm{~mm}$, the particles of the specimen work separately without building up a solid structure. Then, the particles start to work as a continuous structure. Therefore, the translational energy of the structure decreases and the reaction force on the wall starts to increase almost linearly

Using the second scenario, the flexible membranes are introduced immediately after the generation of the particles. The pressure on the membranes and the walls is increased from 0 to $5 \mathrm{kN} / \mathrm{m}$ in the time of $0,4 \mathrm{~s}$. The change of the force acting on the bottom wall during compaction is shown in Fig 9. Comparing this force-displacement curve to the curve obtained by the first scenario (Fig 5, $v=0,01 \mathrm{~m} / \mathrm{s}$ ), we can see that the force acting on the wall increases slightly at the first stage of compaction $(\mathrm{F}=13,9 \mathrm{~N}$ when $u=1,5 \mathrm{~mm})$ while in the first scenario it actually remains equal to zero.

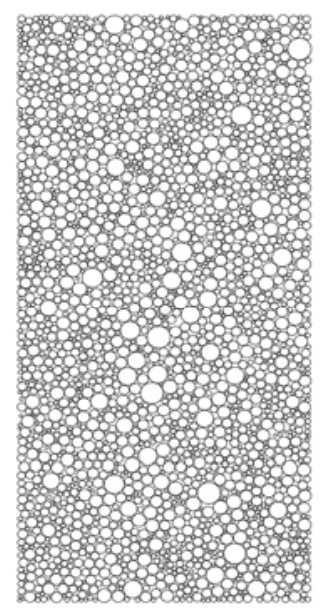

Fig 7. Specimen compacted by moving all four walls according to the first scenario

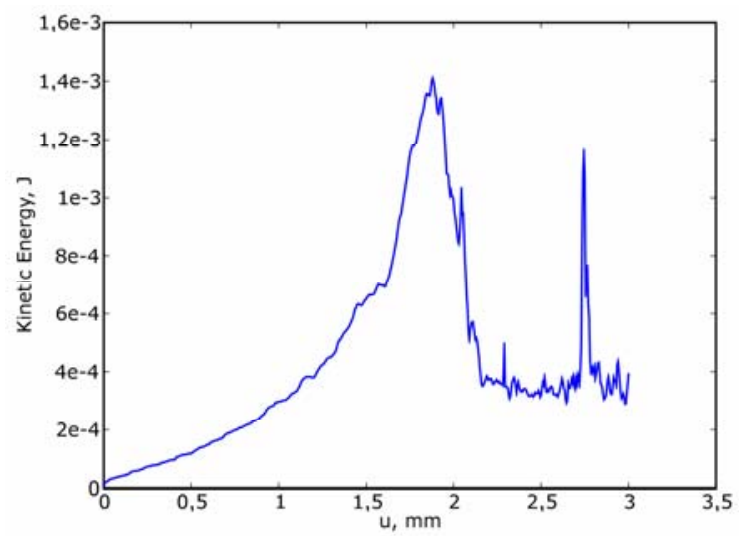

Fig 8. Kinetic translational energy vs displacement 


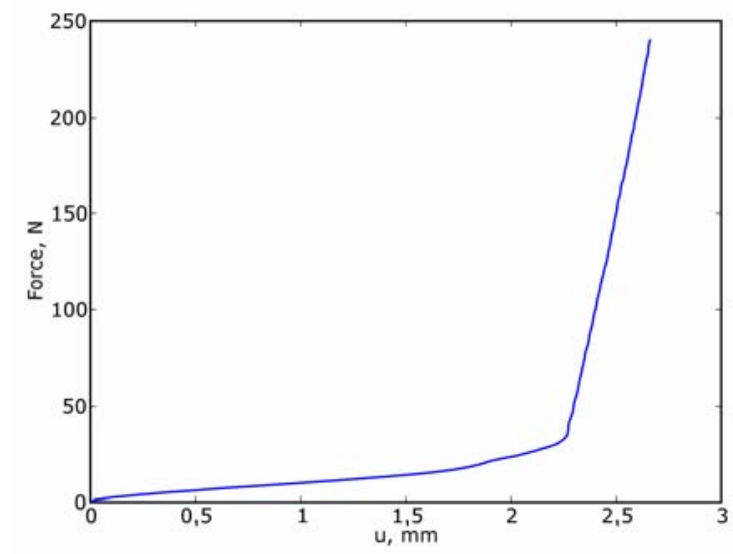

Fig 9. The dependence of the reaction force on the displacement of the boundary according to the second scenario

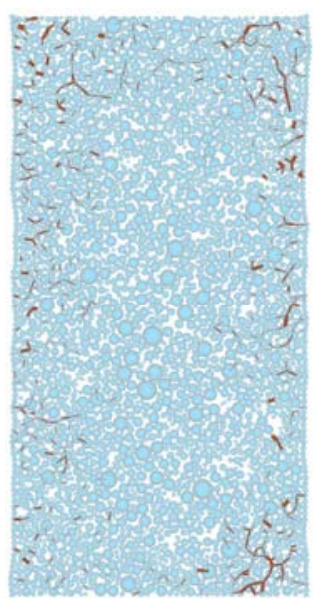

Fig 10. The force network from the second scenario, $u=1 \mathrm{~mm}, F_{\max }=5,41 \mathrm{~N}$

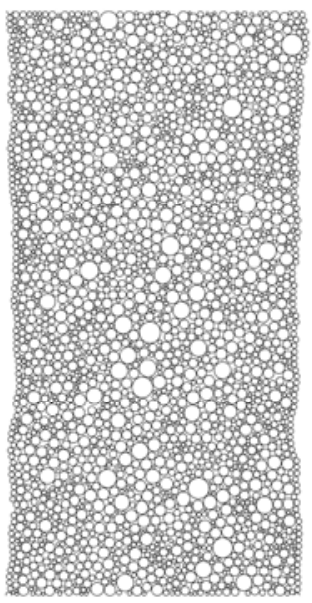

Fig 11. Specimen compacted according to the second scenario
The forces acting between the particles (Fig 10) demonstrate that no considerable network of forces is developed when $\mathrm{u}=1 \mathrm{~mm}$. The compacted specimen shown in Fig 11 has considerably distorted side boundaries. When using this specimen for the biaxial test, these boundaries can influence the result of simulation, therefore the third scenario for specimen compaction is suggested.

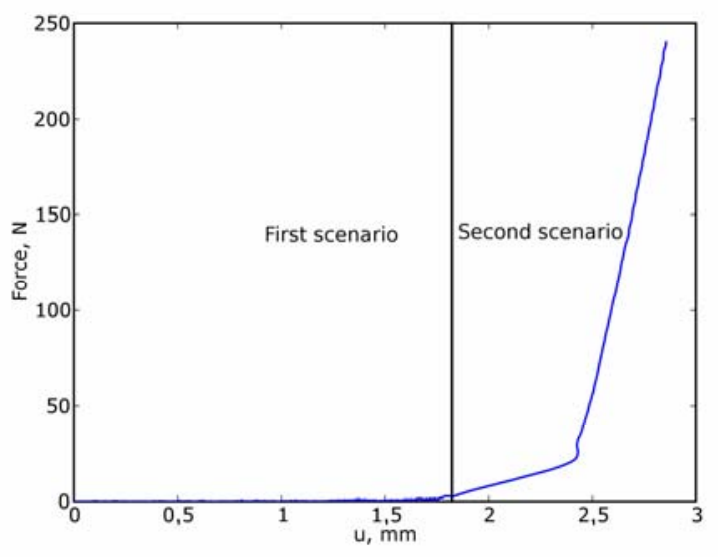

Fig 12. The dependence of reaction force on displacement of the boundary, the third combined scenario

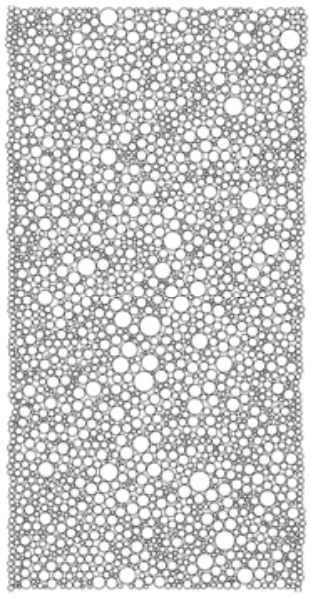

Fig 13. Specimen compacted according to the third scenario

According to the third scenario the specimen is compacted by moving all four walls at the specified speed $(v=0,01 \mathrm{~m} / \mathrm{s})$ until the wall displacement $u=1,8 \mathrm{~mm}$ is reached. Up to this displacement value no significant reaction force is developed (Fig 12). At this point, the side walls are replaced by flexible membranes. The pressure on the membranes and on the top and bottom walls is increased gradually until $p=5 \mathrm{kN} / \mathrm{m}$. The compacted specimen is shown in Fig 13. By comparing this specimen and the specimen obtained using the second scenario, we can see that the side boundaries are more straight. Using this scenario it is easy to vary isotropic pressure on the specimen and to analyse the influence of various factors by ensuring that boundary conditions are the same. 


\section{Conclusions}

Compacting of the particles for the biaxial compression test regarded as a generation of the initial conditions is considered numerically by applying the discrete element method. Simulation of the compacting is performed according to three scenarios. On the basis of the obtained results the following conclusions have been drawn.

1) The first scenario for generating the compacted specimen is implemented by moving rigid walls. The application of this scenario proves the ability to generate the required initial porosity conditions. However, the specimen is sensitive to the loading rate. Therefore, permanent evaluation of the particle state and some control procedures are required.

2) The second scenario for generating the prescribed pressure on the free boundaries is implemented directly by using the model of flexible membranes. It is computationally simple, but it results in an undesirable physical state of the particles.

3) The third scenario combining the compaction by the moving rigid walls at the initial stage and direct compaction by the flexible membrane at the final stage seems to be the most controllable scenario leading to the required initial conditions with physically adjustable state of the particles in the most effective way.

\section{References}

1. Craig, R. F. Craig's Soil Mechanics. London: Spon Press, 2004. 447 p.

2. Shinohara, K.; Oida, M. and Golman, B. Effect of particle shape on angle of internal friction by triaxial compression test. Powder Technology, 107(1-2), 2000, p. 131-136.

3. Lanier, J. and Jean, M. Experiments and numerical simulations with 2D disks assembly. Powder Technology, 109(1-3), 2000, p. 206-221.

4. Cundall, P. A. and Strack, O. D. L. A discrete numerical model for granular assemblies. Geotechnique, 29, 1979, p. 47-65.

5. Sadd, M. H.; Adhikari, G. and Cardoso, F. DEM simulation of wave propagation in granular materials. Powder Technology, 109 (1-3), 2000, p. 222-233.

6. Džiugys, A. and Peters, B. J. An approach to simulate the motion of spherical and non-spherical fuel particles in combustion chambers. Granular Matter, 3(4), 2001, p. 231-266.

7. Langston, P. A.; Al-Awamleh, M. A.; Fraige, F. Y. and Asmar, B. N. Distinct element modelling of nonspherical frictionless particle flow. Chemical Engineering Science, 59(2), 2004, p. 425-435.

8. Luding, S.; Lätzel, M.; Volk, W.; Diebels, S. and Herrmann, H. J. From discrete element simulations to a continuum model. Computer Methods in Applied Mechanics and Engineering, 191(1-2), 2001, p. 21-28.
9. Luding, S. From microscopic simulations to macroscopic material behavior. Computer Physics Communications, 147(1-2), 2002, p. 134-140.

10. Ting, J. M.; Corkum, B. T.; Kauffman, C. R. and Greco, C. Discrete numerical model for soil mechanics. Journal of Geotechnical Engineering, 115(3), 1989, p. 379-398.

11. Sitharam, T. G. Micromechanical modelling of granular materials: effect of confining pressure on mechanical behaviour. Mechanics of Materials, 31(10), 1999, p. 653-665.

12. Liu, S. H.; Sun, D. A. and Wang, Y. Numerical study of soil collapse behavior by discrete element modelling. Computers and Geotechnics, 30(5), 2003, p. 399-408.

13. Jiang, M. J.; Konrad, J. M. and Leroueil, S. An efficient technique for generating homogeneous specimens for DEM studies. Computers and Geotechnics, 30(7), 2003, p. 579-697.

14. Hunt, S. P.; Meyers, A. G. and Louchinikov V. Modelling the Kaiser effect and deformation rate analysis in sandstone using the discrete element method. Computers and Geotechnics, 30(7), 2003, p. 611-621.

15. Iwashita, K. and Oda, M. Micro-deformation mechanism of shear banding process based on modified distinct element. Powder Technology, 109(1-3), 2000, p. 192-205.

16. Mirghasemi, A. A.; Rothenburg, L. and Matyas, E. L. Influence of particle shape on engineering properties of assemblies of two-dimensional polygon-shaped particles. Geotechnique, 52(3), 2000, p. 209-217.

17. Schmitt, A. and Katzenbach R. Particle based modelling of CFA and soil displacement piles. In: Proc of the $4^{\text {rd }}$ International Geotechnical Seminar 'Deep Foundations on Bored and Auger Piles', Ghent, Belgium, June 2-4 2003. Ed. by W. F. Van Impe. Rotterdam: Millpress, 2003, p. 217-225.

18. Tsunekawa, H. and Iwashita, K. Numerical simulation of triaxial test using two and three dimensional DEM. In: Proc. of the 4th International Conference on Micromechanics of Granular Media, Powders and Grains, Swndai, Japan, 21-25 May 2001. Ed. by Y. Kishino. Rotterdam: Balkema, 2001, p. 177-180.

19. Comborde, F.; Mariotti, C. and Donze, F. V. Numerical study of rock and concrete behaviour by discrete element modelling. Computers and Geotechnics, 27(4), 2000, p. 225-247.

20. Balevičius, R.; Džiugys, A. and Kačianauskas, R. Discrete element method and its application to the analysis of penetration into granular media. Journal of Civil Engineering and Management, 10(1), 2004, p. 3-14.

21. Balevičius, R.; Džiugys, A. and Kačianauskas, R. DEMMAT Code for numerical simulation of multiparticle systems dynamics. Information Technology and Control, 34(1), 2005, p. 71-78. 


\section{DALELIŲ TANKINIMAS DISKRETINIŲ ELEMENTŲ METODU DVIAŠIAM KOMPRESIJOS BANDYMUI ATLIKTI \\ D. Markauskas, R. Kačianauskas}

Santrauka

Šiame straipsnyje pateiktas skaitinis dalelių tankinimo modeliavimas diskretinių elementų metodu dviašiam kompresijos bandymui atlikti. Tankinimas nagrinejamas kaip pirmasis nepriklausomas veiksmas, reikalingas, kad būtų galima atlikti viso kompresijos bandymo modeliavimą. Kontinuumo teorijos požiūriu sutankinimas yra pradinių sąlygų generavimas. Nagrinėjami trys skirtingi tankinimo pavyzdžiai keičiant apkrovą. Diskretinių elementų metodologija ir pagrindiniai sąryšiai, taip pat tankinimo problemos formulavimas ir skaičiavimo aspektai čia detaliai išdèstyti. Kiekvieną pavyzdị iliustruoja skaitiniai rezultatai. Tyrimo metu nustatyta, kad, naudojant mišrujji tankinimą, gaunamos reikiamos pradinès sąlygos.

Reikšminiai žodžiai: diskretinių elementų metodas, klampiai tampri granuliuotoji terpè, dviašis bandymas, dalelių tankinimas.

Rimantas KAČIANAUSKAS. Prof Dr Habil at the Dept of Strength of Materials, Senior Researcher at the Laboratory of Numerical Modelling, Vilnius Gediminas Technical University. Author of more than 100 scientific articles, a monograph and a text book. Member expert of Lithuanian Academy of Sciences. Research interests: finite element method, discrete element method, structural engineering mechanics of materials, fracture mechanics, coupled problems.

Darius MARKAUSKAS. Research Fellow at the Laboratory of Numerical Modelling, Vilnius Gediminas Technical University. His research interests include the simulation of materials by discrete element method, the analysis of static and dynamic soil structure interaction by the finite element method. 